EESTI NSV TEADUSTE AKADEEMIA TOIMETISED. XV KOIDE FUUSIKA-MATEMAATIKA- JA TEHNIKATEADUSTE SEERIA, 1966, NR. 2

ИЗВЕСТИЯ АКАДЕМИИ НАУК ЭСТОНСКОН ССР. ТОМ ХV СЕРИЯ ФИЗИКО-МАТЕМАТИЧЕСКИХ И ТЕХНИЧЕСКИХ НАУК. 1966, № 2

Х. ПАЛЬМРЕ

\title{
О ТЕКТОНИЧЕСКОМ НАРУШЕНИИ В РАЙОНЕ ВЫХМА (ЦЕНТРАЛЬНАЯ ӘСТОНИЯ)
}

Тектоническая структура территории Эстонской ССР изучена еще сравнительно мало. Описана она, главным образом, в северной и северо-восточной частях Эстонии, где в связи с интенсивными поисками и разведкой полезных ископаемых выявлен ряд тектонических нарушений.

Р. Вахер, В. Пуура и Э. Эрисалу [1] выделили в Северо-Восточной Эстонии три зоны тектонических нарушений северо-восточного направления, высказав предположение, что некоторые из этих зон протягиваются на юго-запад через Центральную Эстонию. В результате геологических исследований, проводившихся в районе Выхма начиная с 1955 года (рис. 1), нами был собран материал, указывающий на существование таких зон в названном районе.

В новом русле р. Навести встречаются трещины как северо-западного, так и северо-восточного направления. Азимут первых $315^{\circ}$, вторых - в основном $60-65^{\circ}$.

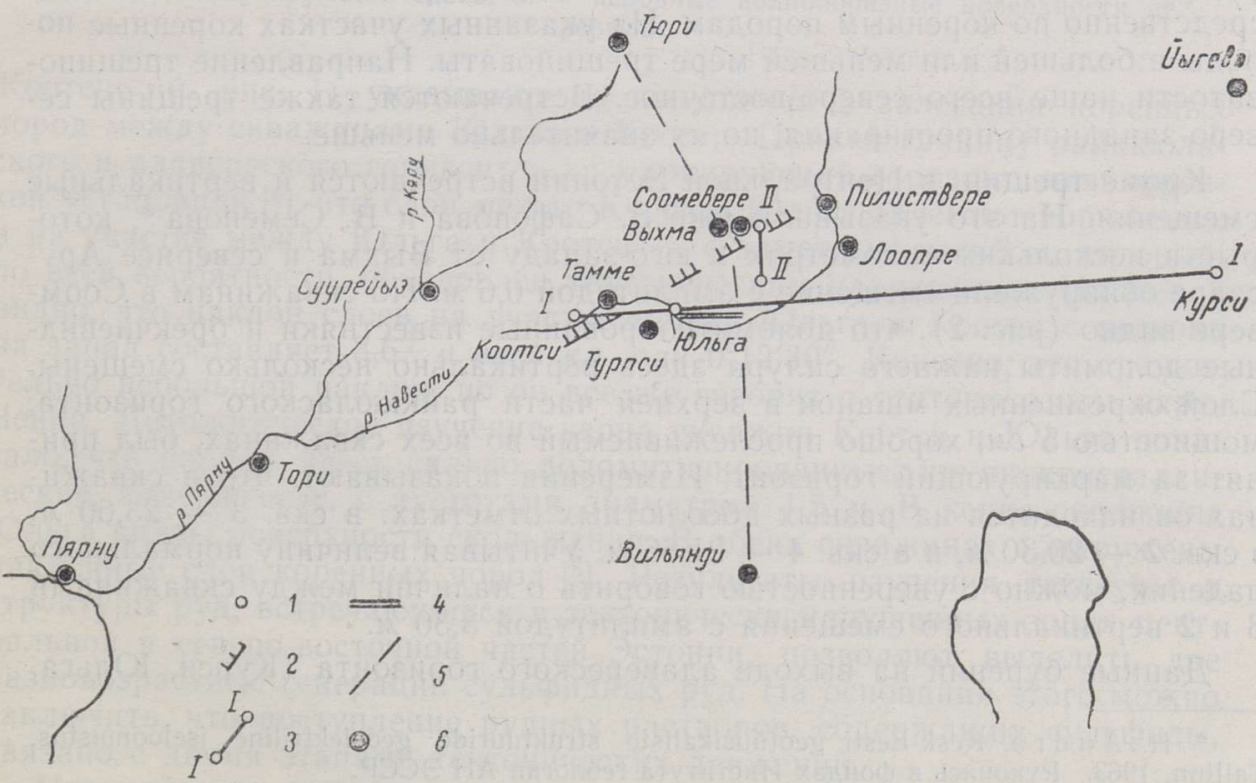

Рис. 1. Схематическая карта тектонических нарушений в окрестности Выхма: 1 - буровая скважина; 2 - намечаемая зона тектонического нарушения; 3 - линия разреза; 4 - углубленное русло р. Навести; 5 - линия железной дороги; 6 - населенные пункты. 
Трещины северо-восточного направления встречаются группами, в которых расстояние между отдельными трещинамй колеблется от 0,2 до 1,0 м. Группы трешин составляют трешиноватые зоны шириной 100 $200 \mathrm{M}$.

По имеющимся данным, таких трещиноватых зон на р. Навести, между скважиной Юльга и железной дорогой, идущей на Вильянди, четыре; они находятся друг от друга на расстоянии $1-2 \kappa м$.

Трещиноватые зоны обычно закарстованы; особенно сильно это заметно в зоне, расположенной в 100 к западу от железной дороги. В пределах зон наблюдается и сульфидное рудопроявление; сульфидные минералы были обнаружены и вне трешиноватой зоны, но в значительно меньших количествах.

Сульфидные рудные минералы, образующие крустификацию, покрывают в большей или меньшей степени стенки узких (1-2 мм) трещин; 5 редких случаях трещины заполнены минералами, образующими мелкие рудные жилы. В залегающих в трещиноватой зоне породах можно было наблюдать поверхности скольжения.

Прямых наблюдений, которые подтвердили бы предположение о том, что эти трещины протягиваются дальше на юго-запад, не производилось. Автор полагает, что зону трешиноватости у скважины Юльга можно проследить на мелиоративной канаве Соомевере, где в коренных породах также развита трещиноватость северо-восточного направления.

На зональную трещиноватость северо-восточного направления в Центральной Эстонии, у Соомевере, указывают также произведенные копки, бурения скважин и электрометрические измерения *

Косвенные указания на наличие тектонических нарушений в коренных породах Центральной Эстонии имеются в работе А. Вельнера [8]. Из данных нивелировки р. Навести видно, что в некоторых местах, например в районе Юльга, Коотси и Тамме, а также у Пилиствере и Лоопpe, река имеет большее падение. Она здесь порожистая и течет непосредственно по коренным породам. На указанных участках коренные породы в большей или меньшей мере трещиноваты. Направление трещиноватости чаще всего северо-восточное. Встречаются также трещины северо-западного простирания, но их значительно меньше.

Кроме трещин, в Центральной Эстонии встречаются и вертикальные смещения. На это указывали уже 3. Сафонова и В. Семенова *, которые в нескольких километрах к юго-западу от Выхма и севернее Арусааре обнаружили смещение с амплитудой 0,6 м. По скважинам в Соомвере видно (рис. 2), что доломитизированные известняки и брекчиевидные доломиты нижнего силура здесь вертикально несколько смещены. Слой окремненных мшанок в верхней части райккюлаского горизонта, мощностью 5 см, хорошо прослеживаемый во всех скважинах, был принят за маркирующий горизонт. Измерения показывают, что в скважинах он находится на разных абсолютных отметках: в скв. $3-23,60 \mu$, в скв. $2-20,30$ м, и в скв. $4-21,66$ м. Учитывая величину нормального падения, можно с уверенностью говорить о наличии между скважинами 3 и 2 вертикального смещения с амплитудой $3,30 \mathrm{~m}$.

Данные бурений на выходе адавереского горизонта (Курси, Юльга,

* H. Andra, Kesk-Eesti geofüüsikaliste struktuuride geoelektriline iseloomustus, Tallinn, 1963. Рукопись в фондах Института геологии АН ЭССР.

* 3. А. С а фоно в а, В. Н. С є м е н в а, О поисковых работах Выхмаского отряда Эстонской партии за 1955 г. (Изучение характера минерализации и морфологии рудных тел Выхмаского месторождения). Рукопись в фондах Управления геологии Эст, CCP. 

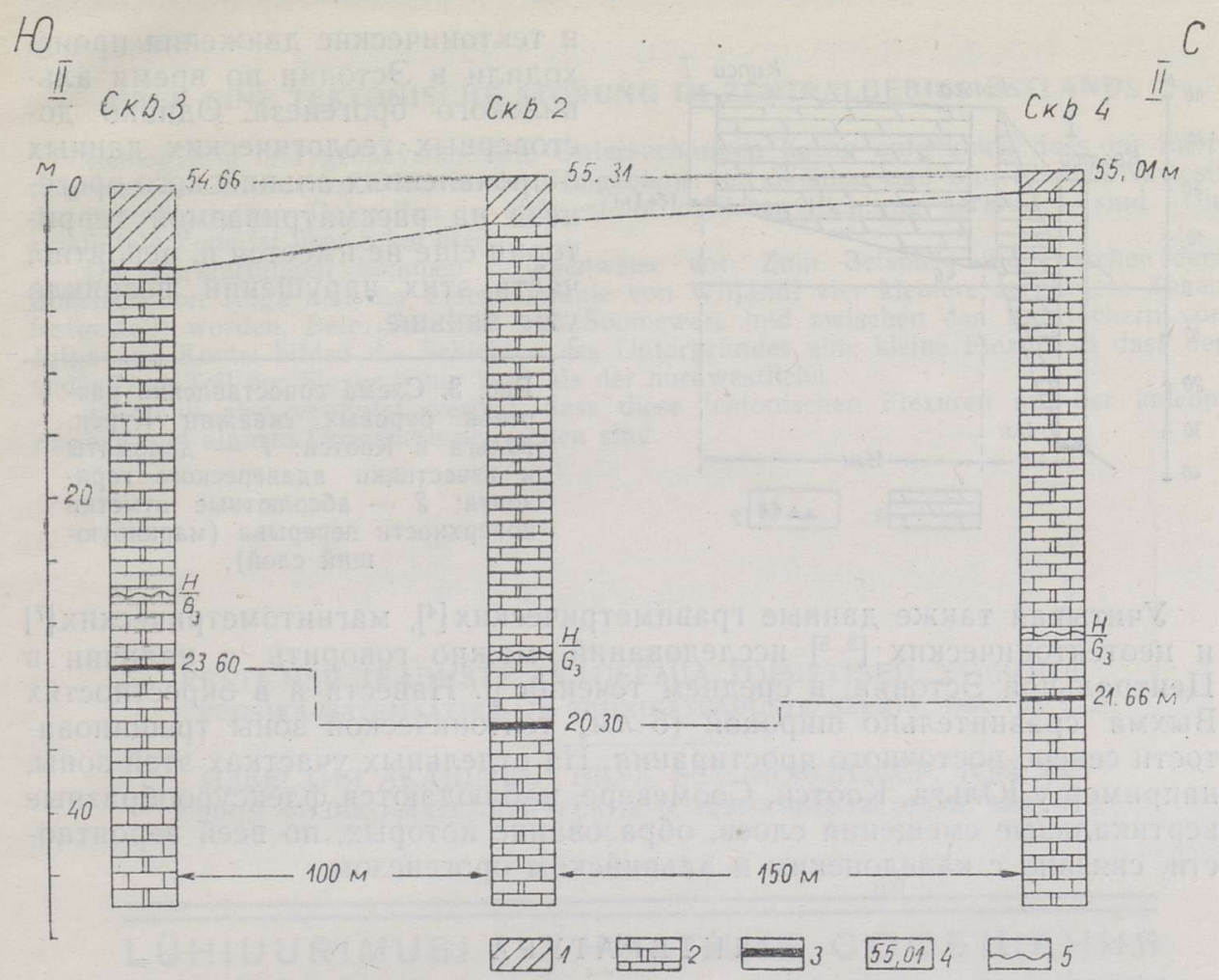

Рис. 2. Схема сопоставления разрезов буровых скважин Соомевере: 1 - четвертичные отложения; 2 - трешиноватые карбонатные породы; 3 - окремненный слой мшанок (маркирующий слой); 4 - абсолютные отметки устьев буровых скважин и маркирующих слоев; 5 - неровные волнообразные поверхности перерыва.

Коотси; см. рис. 1) указывают на нарушения в залегании коренных пород между скважинами Юльга и Коотси. Приняв границу райккюлаского и адавереского горизонтов за маркирующий горизонт, нивелировкой установили [ $\left.{ }^{6}\right]$, что слои между Курси и Юльга залегают нормально, а на участке между Юльга и Коотси - с заметным изгибом, который, по всей вероятности, обусловлен тектоническим нарушением. На рис. 3 видно, что наклон слоев на участке между Юльга и Коотси с востока на запад составляет 3,67 м на 1 км, или $0^{\circ} 12^{\prime} 30^{\prime \prime}$. Конечно, это сравнительно небольшой наклон, но он все же говорит о тектоническом нарушении. Литологическое изучение керна скважин Коотси и Юльга показало, что породы здесь сильно доломитизированные, крупнокристаллические, кавернозные, с пустотами диаметром 1,5 м. В керне скважины Юльга видны поверхности скольжения. В обеих скважинах обнаружены наклонные слои коренных пород [ $\left.{ }^{6}\right]$. Результаты изучения текстуры. й структуры руд, встречающихся в тектонически нарушенных зонах центральной и северо-восточной частей Эстонии, позволяют выделить две разновозрастные генерации сульфидных руд. На основании этого можно заключить, что поступление рудных растворов, содержащих сульфиды, связано с двумя этапами тектонических движений.

Что касается времени тектонических движений, обусловивших описанные выше нарушения, то Г. Гончаров [ $\left.{ }^{2}\right]$, основываясь на данных исследований изотопного состава галенита, полагает, что рудоотложение 


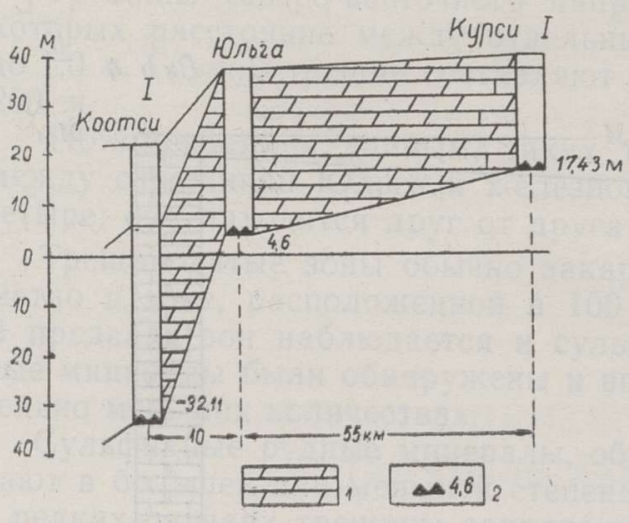

и тектонические движения происходили в Эстонии во время альпийского орогенеза. Однако достоверных геологических данных о проявлениях альпийского орогенеза на рассматриваемой территории еще не имеется и, вероятно, часть этих нарушений возникла уже раньше.

Рис. 3. Схема сопоставления разрезов буровых скважин Курси, Юльга и Коотси: 1 - доломиты и известняки адавереского горизонта; 2 - абсолютные отметки поверхности перерыва (маркиругощий слой).

Учитывая также данные гравиметрических $\left[{ }^{4}\right]$, магнитометрических $\left[{ }^{7}\right]$ и неотектонических $\left[{ }^{3,5}\right]$ исследований, можно говорить о наличии в Центральной Эстонии, в среднем течении р. Навести и в окрестностях Выхма сравнительно широкой $(5$ kм) тектонической зоны трещиноватости северо-восточного простирания. На отдельных участках этой зоны, например у Юльга, Коотси, Соомевере, наблюдаются флексурообразные вертикальные смещения слоев, образование которых, по всей вероятности, связано с каледонским и альпийским орогенезом.

\section{ЛИТЕРА Т У Р А}

1. В а хе р Р. М., Пуура В. А., Эри с алу Э. К., Тектоническое строение СевероВосточной Эстонии, Тр. Ин-та геол. АН ЭССР, Х, 1962.

2. Гон ч а ров Г. С., Проявления полиметаллического оруденения Эстонской ССР, Сов. геол., № $7,1964$.

3. Ж елн и н Г. А., Изучение вертикальных движений земной коры в Эстонской ССР методом повторных нивелировок, Материалы совещания по вопросам неотектонических движений в Прибалтике, Тарту, 1960.

4. $\mathrm{M}$ а а зик В. Я., О гравиметрической разведке полиметаллического рудопроявления в средней части Эстонии, В сб.: Литология палеозойских отложений Әстонии, Таллин, 1964.

5. О р в и ку К. К., О неотектонических движениях в Эстонской ССР на основе геологических данных, Материалы совещания по вопросам неотектонических движений в Прибалтике, Таллин, 1960.

6. П а льм ре Х. Г., К литостратиграфии адавереского горизонта. Тр. Ин-та геол. АН ЭССР, X, 1962.

7. Побул Э. А., Характеристика магнитного поля территории ЭССР, Геология СССР, XXVIII, 1960.

8. W e $1 \mathrm{ln}$ e r, A. Sisevete uurimise andmed I, Kaubandus-Tööstusministeeriumi väljaanne, Tallinn, 1922.

\section{Институт геологии \\ Академии наук Эстонской ССР}

Поступила в редакцию $4 /$ II 1966

\section{H. PALMRE}

\section{TEKTOONILISEST RIKKEST KESK-EESTIS}

Geoloogiliste ja geofüüsikaliste uurimistega on selgitatud, et Eesti NSV keskosas, Navesti jõel ja Vōhma ümbruses, on alamsiluri dolomiidid lổhestatud põhiliselt kirdeedela suunas. Lõhestatud vööndi laius ulatub üle $5 \mathrm{~km}$. Sellel alal esinevad lõhed gruppidena: näit. Julga puuraugu ja Viljandi raudtee vahelises osas on täheldatud neli lõhestatud vöödet. Soomevere juures ning Navesti jōel Julga ja Kootsi vahelises osas moodustavad aluspōhja kihid väikese fleksuuri, mille kagupoolne osa, võrreldes loodepoolsega, asub kõrgemal ning tema kujunemine arvatavasti on seoses kaledoonilise ja alpiinse orogeneesiga. 


\section{H. PALMRE}

\section{OBER EINE TEKTONISCHE STÖRUNG IM ZENTRALGEBIET ESTLANDS}

Geologische und geophysikalische Untersuchungen haben aufgeklärt, dass im Zentralgebiet der Estnischen SSR, in der Umgebung von Wõhma und am Flusse Nawesti die untersilurischen Dolomiten in südwest-nordöstlicher Richtung zerklüftet sind. Die zerklüftete Zone ist über $5 \mathrm{~km}$ breit.

Die Zerklüftungen kommen gruppenweise vor. Zum Beispiel sind zwischen dem Bohrloch von Julga und der Eisenbahnlinie von Wiljandi vier kleinere zerklüftete Zonen festgestellt worden. Beim Bohrloch von Soomewere und zwischen den Bohrlöchern von Julga und Kootsi bilden die Schichten des Untergrundes eine kleine Flexur, so dass der südöstliche Teil der Flexur höher liegt als der nordwestliche.

Es kann also vermutet werden, dass diese tektonischen Flexuren mit der kaledonischen und alpinen Orogenese verbunden sind.

EESTI NSV TEADUSTE AKADEEMIA TOIMETISED. XV KÖIDE

FOOSIKA-MATEMAATIKA- JA TEHNIKATEADUSTE SEERIA, 1966, NR. 2

ИЗВЕСТИЯ АКАДЕМИИ НАУК ЭСТОНСКОИ ССР. ТОМ ХV

СЕРИЯ ФИЗИКО-МАТЕМАТИЧЕСКИХ И ТЕХНИЧЕСКИХ НАУК. 1966, № 2

\section{LÜHIUURIMUSI * KPATHИE СООБЩЕНИЯ}

A. ПУРГА

\section{ВРЕМЕННАЯ ЗАВИСИМОСТЬ ВТОРИЧНОГО СВЕЧЕНИЯ ПРИ ВОЗБУЖДЕНИИ ФОТОННЫМ ПАКЕТОМ}

В течение нескольких постедних лет ведутся интенсивные экспериментальные и теоретические исследования интерференционных явлений при квантовых переходах (см. обзор [1]). В отличие от обынной теории [4], где рассматриваются переходы между стационарными состояниями системы, теория интерференционных явлений занимается исследованием квантовых переходов между нестационарными состояниями. Из более новых результатов в этой области можно отметить работы [2,3], в которых развивается теория излучательных переходов и спектра испускания с нестационарного возбужденного состояния.

Рассмотрим временную зависимость спектра испускания некоторой квантовой системы при возбуждении фотонным пакетом. Ограничимся рассмотрением однофотонных состояний поля излучения, т. е. предполагаем, что решение $\Psi(t)$ уравнения Шредингера

$$
i \hbar \frac{\partial \Psi(t)}{\partial t}=\left(H_{0}+V_{I}+\sum_{x} \hbar \omega_{x} a_{x}^{+} a_{x}\right) \Psi(t)
$$

может быть представлено в виде

$$
\Psi(t)=e^{-\frac{i}{\hbar} H_{0} t}\left[\psi_{0}(t) \Phi_{0}+\sum_{x} e^{-i \omega_{x} t} a_{x}^{+} \Phi_{0} \psi_{x}(t)\right] .
$$

9 ENSV TA Toimetised F-2 66 
Здесь $a_{x}$ и $a_{x}^{+}$- операторы вторичного квантования электромагнитного поля (индекс $x$ объединяет индексы поляризации $\lambda$ и волнового вектора $\vec{k}) ; H_{0}$ - гамильтониан излучателя; $V_{I}$ - оператор взаимодействия излучателя с электромагнитным полем; $\Phi_{0}$ - вакуумный функционал электромагнитного поля. Функции $\psi_{0}(t)$ и $\psi_{x}(t)$ удовлетворяют системе уравнений

$$
\left\{\begin{array}{l}
i \hbar \frac{\partial \psi_{0}}{\partial t}=e^{\frac{i}{\hbar} H_{0} t}\left\langle\Phi_{0}\left|V_{I}\right| \Phi_{0}\right\rangle e^{-\frac{i}{\hbar} H_{0} t} \psi_{0}+ \\
+\sum_{x} e^{-i \omega_{x} t} e^{\frac{i}{\hbar} H_{0} t}\left\langle\Phi_{0}\left|V_{I} a_{x}^{+}\right| \Phi_{0}\right\rangle e^{-\frac{i}{\hbar} H_{0} t} \psi_{x} \\
i \hbar \frac{\partial \Psi_{x}}{\partial t}=e^{i \omega_{x} t} e^{\frac{i}{\hbar} H_{0} t}\left\langle\Phi_{0}\left|a_{x} V_{I}\right| \Phi_{0}\right\rangle e^{-\frac{i}{\hbar} H_{0} t} \psi_{0}+ \\
+\sum_{x^{\prime}} e^{i\left(\omega_{x}-\omega_{x^{\prime}}\right) t} e^{\frac{i}{\hbar} H_{0} t}\left\langle\Phi_{0}\left|a_{\downarrow} V_{I} a_{x^{\prime}}^{+}\right| \Phi_{0}\right\rangle e^{-\frac{i}{\hbar} H_{0} t} \psi_{x^{\prime}}
\end{array}\right.
$$

Учитывая члены второго порядка по постоянной тонкой структуре $\varepsilon$, гамильтониан взаимодействия $V_{I}$ может быть представлен в виде

$$
\begin{aligned}
& V_{I}=\varepsilon \sum_{x}\left(M(x) a_{x}+\bar{M}(x) a_{x}^{+}\right)+\varepsilon^{2} \sum_{x^{\prime} x^{\prime \prime}} M_{x^{\prime} x^{\prime \prime}}\left(e^{i\left(\overrightarrow{k^{\prime}}+\vec{k}^{\prime \prime}\right) \vec{r}} a_{x^{\prime}} a_{x^{\prime \prime}}+\right. \\
& \left.+e^{i\left(\overrightarrow{k^{\prime}}-\vec{k}^{\prime \prime}\right) \vec{r}} a_{x^{\prime}} a_{x^{\prime \prime}}^{+}+e^{-\overrightarrow{i\left(k^{\prime}-\vec{k}^{\prime \prime}\right) r}} a_{x^{\prime}}^{+} a_{x^{\prime \prime}}+e^{-i\left(\overrightarrow{k^{\prime}}+\overrightarrow{\left.k^{\prime \prime}\right) r}\right.} a_{x^{\prime}}^{+} a_{x^{\prime \prime}}^{+}\right) .
\end{aligned}
$$

Здесь операторы $M(x)$ и $\bar{M}(x)$ действуют только на переменные излучателя, $M_{x^{\prime} x^{\prime \prime}}=M_{x^{\prime \prime} x^{\prime}}$ - действительная величина, не содержащая переменных излучателя.

Рассмотрим волновые функции $\psi_{x}(t)$ с квантовыми числами $\nsim$, которые не принадлежат исходному волновому пакету

$$
\left.\Psi(0)=\sum_{x^{\prime}} c_{x^{\prime}} a_{x^{\prime}}^{+} \Phi_{0} n_{0}\right\rangle,
$$

где $\left|n_{0}\right\rangle$ собственное состояние гамильтониана $H_{0}$. Тогда из системы (1) в первом ненулевом приближении по степеням $\varepsilon$ получим

$$
\begin{gathered}
\psi_{x}(t)=-\frac{\varepsilon^{2}}{\hbar{ }^{2}} \sum_{x^{\prime}} c_{x^{\prime}} \int_{0}^{t} d \tau \int_{0}^{\tau} d \tau_{1} e^{i \omega_{x^{\tau}}} e^{-i \omega_{x^{\prime}} \tau_{1}} e^{\frac{i}{\hbar} H_{0} \tau} \bar{M}(x) e^{-\frac{i}{\hbar} H_{0}\left(\tau-\tau_{1}\right)} \times \\
X M\left(x^{\prime}\right) e^{-\frac{i}{\hbar} H_{0} \tau_{1}}\left|n_{0}\right\rangle-2 i \frac{\varepsilon^{2}}{\hbar} \sum_{x^{\prime}} c_{x^{\prime}} M_{x^{\prime} x} e^{i\left(k^{\prime}-\vec{k}\right) \vec{r}} \int_{0}^{t} e^{i\left(\omega_{x}-\omega_{x^{\prime}}\right) \tau} d \tau\left|n_{0}\right\rangle .
\end{gathered}
$$

Интенсивность вторичного свечения

$$
I_{t}(x)=\frac{d}{d t}\left\langle\psi_{x}(t) \mid \psi_{x}(t)\right\rangle
$$


имеет в том же приближении в представлении собственных функций гамильтониана $H_{0}$ следуюший вид:*

$$
\begin{aligned}
& I_{t}(x)=I_{t}^{l}(x)+I_{t}^{k}(x)+I_{t}^{0}(x) \\
& I_{t}^{l}(x)=\frac{1}{\hbar^{2}} \sum_{m} \sum_{r s} e^{i \omega_{s r} t} \sum_{x^{\prime} x^{\prime \prime}} c_{x^{\prime}} c_{x^{n}}^{*} A_{x^{\prime} x^{\prime \prime}}^{r s}(\chi, m)\left[\bar{\zeta}\left(\omega_{x}-\omega_{s m}\right)+\bar{\zeta}^{*}\left(\omega_{x}-\omega_{r m}\right)\right] ; \\
& I_{t}^{k}(x)=\frac{1}{\hbar^{2}} \sum_{m} \sum_{x^{\prime} x^{\prime \prime}} c_{x^{\prime}} c_{x^{\prime \prime}}^{*} e^{i\left(\omega_{x^{\prime \prime}}-\omega_{x^{\prime}}\right) t} B_{x^{\prime} x^{\prime \prime}}(x, m)\left[\bar{\zeta}\left(\omega_{x}-\omega_{x^{\prime}}+\omega_{m n_{0}}\right)+\right. \\
& \left.+\bar{\zeta}^{*}\left(\omega_{x}-\omega_{x^{\prime}}+\omega_{m n_{0}}\right)\right] \\
& I_{t}^{0}(x)=\frac{1}{\hbar^{2}} \sum_{x^{\prime} x^{\prime \prime}} c_{x^{\prime}} c_{x^{\prime \prime}}^{*} e^{l\left(\omega_{x^{\prime \prime}}-\omega_{x^{\prime}}\right) t}\left[B_{x^{\prime} x^{\prime \prime}}\left(x, n_{0}\right)+\right. \\
& \left.+C_{x^{\prime} x^{\prime \prime}}\left(x, n_{0}\right)+D_{x^{\prime} x^{\prime \prime}}\left(x, n_{0}\right)\right]\left[\bar{\zeta}\left(\omega_{x}-\omega_{x^{\prime}}\right)+\bar{\zeta}^{*}\left(\omega_{x}-\omega_{x^{\prime \prime}}\right)\right] .
\end{aligned}
$$

Здесь использованы следующие обозначения:

$$
\begin{gathered}
A_{x^{\prime} x^{\prime \prime}}^{r s}(x, m)=\frac{1}{\hbar^{2}} \frac{\varepsilon^{4} M_{n_{0} s}^{+}\left(x^{\prime \prime}\right) \bar{M}_{s m}^{+}(x) \bar{M}_{m r}(x) M_{r n_{0}}\left(x^{\prime}\right)}{\left(\omega_{x^{\prime \prime}}-\omega_{s n_{0}}\right)\left(\omega_{x^{\prime}}-\omega_{r n_{0}}\right)} ; \quad B_{x^{\prime} x^{\prime \prime}}(x, m)=\sum_{r, s} A_{x^{\prime} x^{\prime \prime}}^{r s}(x, m) ; \\
C_{x^{\prime} x^{\prime \prime}}\left(x, n_{0}\right)=\frac{2 \varepsilon^{4}}{\hbar}\left[M^{*}\left(x^{\prime \prime} x\right) \sum_{r} \frac{\bar{M}_{n_{0} r}(x) M_{r n_{0}}\left(x^{\prime}\right)}{\omega_{x^{\prime}}-\omega_{r n_{0}}}+M\left(x^{\prime} x\right) \sum_{r} \frac{M_{n_{0} r^{\prime}}^{+}\left(x^{\prime \prime}\right) \bar{M}_{r n_{0}}^{+}(x)}{\omega_{x^{\prime \prime}}-\omega_{r n_{0}}}\right] \\
D_{x^{\prime} x^{\prime \prime}}\left(x, n_{0}\right)=4 \varepsilon^{4} M\left(x^{\prime} x\right) M^{*}\left(x^{\prime \prime} x\right) ; \quad M\left(x^{\prime} x^{\prime \prime}\right)=M_{x^{\prime} x^{\prime \prime}} e^{i\left(k^{\prime}-k^{\prime \prime}\right) R} \vec{R} \\
\bar{\zeta}(x)=i \zeta(x)=\pi \delta(x)+i \frac{P}{x} ; \quad \omega_{k l}=\frac{E_{k}-E_{l}}{\hbar} ;
\end{gathered}
$$

$\vec{R}$ - средняя координата электрона излучателя.

Из формулы (3) следует, что вторичное свечение можно разделить на две части. Первая часть $I_{t}^{l}(x)$ показывает, что фотонный пакет возбуждает в системе нестационарное состояние, временное развитие которого (в том числе квантовые биения и релаксация) через функцию $\sum_{r, s} e^{i \omega_{s} r^{t}} A_{x^{\prime} x^{\prime \prime}}^{r s}(x, m)$ отражается во вторичном свечении. Остальная же часть вторичного свечения $I_{t}^{k}(x)+I_{t}^{0}(x)$ содержит лишь временное развитие фотонного пакета $\sum_{x^{\prime} x^{\prime \prime}} c_{x^{\prime}} c_{x^{\prime \prime}}^{*} e^{i\left(\omega_{x^{\prime \prime}}-\omega_{x^{\prime}}\right)^{t}}$ и не отражает происходящих внутри излучателя временных процессов. Таким образом, временной спектр испускания (3) может служить удобной основой для разделения

- Выражение интенсивности $I_{t}(x)$ за единицу времени получено, как обычно [2], для промежутков времени существенно больше «атомного периода $\tau_{n}=\hbar \quad / E_{n}$, где $E_{n}$ - собственное значение энергии системы в возбужденном стационарном состоянии. Из сделанного при решении системы (1) приближения следует также, что в выражении интенсивности (3) не учитывается затухание возбужденных уровней в резуліьтате излучательных переходов.

$9^{\star}$ ENSV TA Tolmetised F -266 
вторичного свечения на люминесценцию $I_{t}^{l}(x)$ и на рассеяние $I_{t}^{k}(x)+$ $+I_{t}^{0}(x)$. Из формулы (3) следует также, что при монохроматическом возбуждении $\left(c_{\mathrm{x}}=\delta_{x \mathrm{x}_{0}}\right) I_{t}^{k}(x)$ сводится к исходной формуле теории комбинационного рассеяния [5], в то время как $I_{t}^{0}(x)$ описывает рассеяние без изменения частоты. Отметим, что такое разделение вторичного свечения на рассеяние и люминесценцию хорошо согласуется с соответствующими результатами работ Б. Степанова и П. Апанасевича [6], где существенной отличительной чертой люминесценции как части вторичного свечения является проявление промежуточных процессов. Отличие заключается в том, что если у Б. Степанова и П. Апанасевича промежуточные процессы возникают лишь под влиянием внешнего по отношению к излучателю возмущения, то в нашей работе они имеют место как естественный процесс изоэнергетического развития нестационарного состояния сложной системы. Причина возникновения такого процесса заложена в импульсной природе возбуждающего волнового пакета, приготовленного для данного эксперимента.

В заключение приношу искренную благодарность К. К. Ребане за руководство настоящей работой.

\section{ЛИТЕРАТУРА}

1. Подгорецкий М. И., Х руст алев О. А., Усп. физ. наук, 81, 217 (1963).

2. Пу р г а А. П., Тр. ИФА АН ЭССР, № 25, 109 (1964).

3. B i e r m a n A. J., Chem. Phys., 43, 1662 (1965).

4. Г а й т ле р В., Қвантовая теория излучения, М., 1956.

5. Л у б ченко А. Ф., П а в лик Б. М., ФТТ, 5, 1714 (1963).

6. С те п анов Б. И., А п н а с в ич П. А., ДАН СССР, 116, 772 (1957); Изв. АН СССР. Сер. физ., 22, 1380 (1958).

Ннститут физики и астрономии

Академии наук Эстонской ССР

Поступила в редакцию 28/III 1966

\section{A. PURGA}

\section{FOOTONPAKETI POOLT ERGUTATUD SEKUNDAARSE KIIRGUSE AJALISEST SOLTUVUSEST}

Häiritusteooria teises lähenduses on tuletatud valem footonpaketi poolt ergutatud sekundaarse kiirguse ajalise sõltuvuse jaoks. Lähtudes ajalise sõltuvuse iseloomust, saab kogu sekundaarset kiirgust loomulikul viisil jaotada kahte ossa. Esimeses osas peegeldub kiirguse ajalises sõltuvuses kvantsüsteemi sisemine ajaline areng mittestatsionaarses olekus, teine osa sisaldab hajumisprotsessis moonutatud footonpaketi arengut. Selline jaotus on sobivaks aluseks sekundaarse kiirgusprotsessi klassifitseerimisel hajumiseks ja luminestsentsiks.

\section{A. PURGA}

\section{TIME DEPENDENCE OF PHOTON PACKET EXCITED SECONDARY EMISSION}

The interaction of the radiation wave packet with a quantum system in the secondorder perturbation theory is considered. A formula for the time dependence of secondary emission rate spectrum is derived. The temporal evolution process promises, in a natural way, a dividing of the transformed light into two parts, one of which reflects the isoenergetic evolution of the photon wave packet excited nonstationary state of the quantum system, whereas the second part contains the temporal evolution of the photon packet distorted by scattering. On the basis of such a division, the secondary emission of light can be classified into scattering and photoluminescence. 